\title{
Misconceptions about efficacy of mammography screening: a public health dilemma
}

\author{
E Chamot, T V Perneger
}

\begin{abstract}
Objective-This study assessed accuracy of women's opinions about reduction in mortality from breast cancer attributable to mammography screening.

Design-Cross sectional survey.

Setting-General population of Geneva, Switzerland.
\end{abstract}

Participants-895 randomly selected women aged 40 to 80 years, free of breast cancer.

Results-Women estimated the proportion of deaths from breast cancer that regular mammography screening prevents in women over age 50 . Only $19.3 \%$ of the respondents assessed screening efficacy realistically (that is, reduction by about one fourth); $52.0 \%$ overestimated efficacy; $26.0 \%$ "didn't know", and $2.6 \%$ stated that screening prevents no death. Women who believed mammography screening to be effective had more positive attitudes toward screening (higher scores of pros and lower scores of cons) and were more likely to plan to have a mammogram (both $p<0.001$ ). Lack of opinion about the benefit of mammography screening was more common among women who had not consulted a gynaecologist recently $(p=0.02)$ nor had had a mammogram during the past two years $(p=0.009)$, who had no opinion about their risk of breast cancer $(p<0.001)$, and who were 70 to 80 years old $(p=0.04)$. Compared with women who provided realistic estimates of screening efficacy, those who overestimated efficacy believed to be at higher risk of breast cancer than other women $(p=0.04)$ and were more likely to be Swiss nationals $(\mathrm{p}=0.001)$.

Conclusions-Most women overestimated and many were uninformed about the efficacy of mammography screening. Therefore, few women were able to take truly informed decisions about screening mammography.

(F Epidemiol Community Health 2001;55:799-803)

The current ethos of public health requires that informed consent be given by the users of any health intervention. ${ }^{1}$ This obligation is even stronger when prospective users do not actively seek help, as often happens with screening. Exactly what information should be given and how remains controversial. The debate reflects the conflict between two equally worthy goals: respect of individual autonomy and greater public health effectiveness. ${ }^{2}$ On the one hand, potential users of screening services should have a clear idea about the benefits and the risks of the procedure; on the other hand, to increase screening coverage and the resulting benefit to the population, most screening programmes engage in promotional activities that favour the more positive messages regarding the intervention.

Mammography screening provides a good illustration of this problem. Information about mortality reduction attributable to mammography screening is often omitted from pamphlets aimed at prospective participants, and when mentioned, mortality reduction is often overstated. ${ }^{34}$ Media coverage of mammography screening similarly favours one sided messages promoting screening. ${ }^{5}$ Whether the opinions of women in the general population reflect such partial information is largely unknown.

This study assessed opinions of women in the general population of Geneva, Switzerland, about the reduction in mortality from breast cancer attributable to mammography screening. Furthermore, as accurate perception of screening efficacy is necessary for the provision of an informed decision, ${ }^{6}$ we also sought to identify women's characteristics associated with lack of opinion about and overestimation of benefits attributable to mammography screening.

\section{Methods}

SETTING

The study took place during the first trimester of 1998 in Geneva, Switzerland. At that time, no local guidelines regarding breast cancer screening were in effect, and the basic health insurance package did not cover the costs of mammography screening. Geneva authorities launched an organised programme of mammography only one year later. The programme proposed a screening mammogram every two years to all residing women of ages 50 to 70 years. Free screening mammograms have been available since January 2001.

\section{DESIGN}

We conducted a cross sectional survey of the knowledge, attitudes, and practices related to mammography screening among women aged 40 to 80 years residing in Geneva. Study participants were selected randomly from the official register of the Geneva Population Bureau. The study was approved by the Geneva Review Board on Research in Epidemiology and Public Health. The survey sample of 1400 was drawn at random from the official population registry. The final questionnaire was sent by mail and up to three reminders were posted to non-respondents. 
Table 1 Perceived efficacy of mammography screening to reduce death due to breast cancer in a random sample of 895 women of ages 40 to 80 years residing in Geneva, Switzerland*

In your opinion, does mammography screening prevent death from breast cancer in women over age 50 ?

\begin{tabular}{lll} 
Number & $\%$ & $\begin{array}{l}\text { Exact 95\% confidence } \\
\text { intervals }\end{array}$ \\
\hline 23 & 2.6 & $(1.6,3.8)$ \\
173 & 19.3 & $(16.5,21.7)$ \\
266 & 29.7 & $(26.3,32.3)$ \\
200 & 22.3 & $(19.3,24.8)$ \\
233 & 26.0 & $(22.8,28.6)$ \\
\hline
\end{tabular}

*Women who reported a history of breast cancer $(n=43)$ or had a missing perceived efficacy of mammography screening $(n=14)$ were excluded.

Table 2 Characteristics associated with lack of opinion about efficacy of mammography screening to prevent deaths due to breast cancer in a random sample of 895 women of ages 40 to 80 years residing in Geneva, Switzerland*

\begin{tabular}{|c|c|c|c|c|}
\hline \multirow[b]{2}{*}{ Characteristic } & \multirow{2}{*}{$\begin{array}{l}\text { Totalt } \\
\text { Number } \\
\text { (column \%) }\end{array}$} & \multicolumn{2}{|c|}{$\begin{array}{l}\text { No opinion about efficacy of } \\
\text { mammography screening }\end{array}$} & \multirow[b]{2}{*}{ p Value } \\
\hline & & Number & Raw \% & \\
\hline Overall & $895(100)$ & 233 & 26.0 & \\
\hline Pros (approximate tertiles) & & & & $<0.001$ \\
\hline Lowest & $363(41.3)$ & 136 & 37.5 & \\
\hline Middle & $231(26.3)$ & 38 & 16.5 & \\
\hline Highest & $286(32.5)$ & 51 & 17.8 & \\
\hline Cons (approximate tertiles) & & & & $<0.001 \ddagger$ \\
\hline Lowest & $310(35.1)$ & 41 & 13.2 & \\
\hline Middle & $293(33.2)$ & 73 & 24.9 & \\
\hline Highest & $279(31.6)$ & 111 & 39.8 & \\
\hline $\begin{array}{l}\text { Reluctant to pay Swiss Fr } 200 \text { for a } \\
\text { mammogram } \$\end{array}$ & & & & 0.01 \\
\hline Yes & $111(14.4)$ & 36 & 32.4 & \\
\hline No & $659(85.6)$ & 148 & 22.5 & \\
\hline $\begin{array}{l}\text { Perceived an organised programme of } \\
\text { mammography screening as useful for } \\
\text { themselves }\end{array}$ & & & & $<0.001$ \\
\hline Yes & $653(79.4)$ & 142 & 21.7 & \\
\hline No & $169(20.6)$ & 64 & 37.9 & \\
\hline $\begin{array}{l}\text { Intended to have a mammogram in the } \\
\text { future }\end{array}$ & & & & $<0.001$ \\
\hline Yes & $584(69.4)$ & 116 & 19.9 & \\
\hline No & $258(30.6)$ & 102 & 39.5 & \\
\hline First degree relative with breast cancer & & & & 0.31 \\
\hline Yes & $64(7.2)$ & 13 & 20.3 & \\
\hline No & $831(92.8)$ & 220 & 26.5 & \\
\hline $\begin{array}{l}\text { Subjective risk of breast cancer as } \\
\text { compared with other women }\end{array}$ & & & & $<0.001$ \\
\hline Lower & $128(14.7)$ & 29 & 22.7 & \\
\hline Similar & $419(48.2)$ & 79 & 18.9 & \\
\hline Higher & $52(6.0)$ & 4 & 7.7 & \\
\hline No opinion & $270(31.1)$ & 107 & 39.6 & \\
\hline $\begin{array}{l}\text { Have had a mammogram in the past two } \\
\text { years }\end{array}$ & & & & $<0.001$ \\
\hline Yes & $406(45.4)$ & 73 & 18.0 & \\
\hline No & $489(54.6)$ & 160 & 32.7 & \\
\hline $\begin{array}{l}\text { Visit to a gynaecologist during the past } \\
\text { year }\end{array}$ & & & & $<0.001$ \\
\hline Yes & $656(80.9)$ & 139 & 21.2 & \\
\hline No & $155(19.1)$ & 61 & 39.4 & \\
\hline $\begin{array}{l}\text { Mammography recommended by a } \\
\text { gynaecologist during past two years }\end{array}$ & & & & $<0.001$ \\
\hline Yes & $423(51.3)$ & 77 & 18.2 & \\
\hline No & $401(48.7)$ & 130 & 32.4 & \\
\hline Age (y) & & & & $<0.001$ \\
\hline $40-49$ & $291(32.5)$ & 77 & 26.5 & \\
\hline $50-69$ & $480(53.6)$ & 100 & 20.8 & \\
\hline $70-80$ & $124(13.9)$ & 56 & 45.2 & \\
\hline Married & & & & 0.007 \\
\hline Yes & $556(62.5)$ & 128 & 23.0 & \\
\hline No & $334(37.5)$ & 105 & 31.4 & \\
\hline Citizenship & & & & 1.0 \\
\hline Swiss & $686(76.9)$ & 179 & 26.1 & \\
\hline Other & $206(23.1)$ & 54 & 26.2 & \\
\hline Education level (y) & & & & 0.03 \\
\hline$\leqslant 10$ & $248(29.6)$ & 75 & 30.2 & \\
\hline$>10$ & $591(70.4)$ & 135 & 22.8 & \\
\hline $\begin{array}{l}\text { Monthly net income per person (Swiss } \\
\text { Fr) }\end{array}$ & & & & 0.12 \\
\hline$\leqslant 2500$ & $169(23.4)$ & 49 & 29.0 & \\
\hline$>2500$ & $554(76.6)$ & 127 & 22.9 & \\
\hline
\end{tabular}

*Women who reported a history of breast cancer $(n=43)$ or had a missing perceived efficacy of mammography screening $(n=14)$ were excluded. + As a result of missing data, numbers may sum to less than 895 . $\ddagger \chi^{2}$ test of linear trend. \Amount charged for a screening mammogram in Geneva. IIn December 2000, 1 Swiss Fr was equal to $£ 0.40$.
SURVEY INSTRUMENT

The questionnaire included a multiple choice item asking about the proportion of deaths from breast cancer that mammography screening every two years prevents in women over age 50. The response choices were: "don't know", "none", "about one fourth", "about one half", and "about three fourths" of deaths. Based on a recent meta-analysis by Kerlikowske et $a l^{7}$ "about one fourth of deaths" was considered to be the correct answer.

Attitudes toward mammography screening were measured with Rakowski's scales of pros and $\operatorname{cons}^{8}$ and three items probing reluctance to pay for a mammogram, perceived usefulness of an organised programme of mammography screening for oneself, and intention to undergo mammography in the future. Rakowski's scales of pros and cons derive from the application of the transtheoretical model of behaviour change to mammography screening, ${ }^{9}{ }^{10}$ and assess attitudes respectively favourable and unfavourable toward mammography screening. Examples of items are: "Having a regular mammogram will give you a feeling of control over your health" (pros), and "You would probably not have a mammogram unless you had a problem with your breasts" (cons). These scales have been used extensively and have shown good psychometric properties, ${ }^{8}{ }^{11-14}$ including in our sample (forthcoming). Subjective risk of breast cancer was assessed by asking women how likely they believed they might get breast cancer as compared with other women. History of breast cancer among first degree relatives (mother and sisters) was included as a crude indicator of objective risk.

Other questions assessed women's experience with preventive healthcare services (mammography in the past two years, recent visits to a gynaecologist, and gynaecologist recommendation for mammography) and sociodemographic characteristics (age, marital status, citizenship, education level, and income).

The survey instrument was pre-tested on a sample of health workers and women from the target population. Items originally written in English (pros and cons) were translated into French by the two authors and a professional translator. The best formulation was selected during a consensus meeting.

\section{ANALYSIS}

We described the distribution of responses to the question about breast cancer deaths prevented and provided exact $95 \%$ confidence intervals for the estimated proportions. To identify predictors of avowed ignorance of screening efficacy, we compared women who responded "don't know" to all others. Then, because few women believed mammography to be ineffective, we excluded the latter from further analysis and compared women who exaggerated mortality reduction to those who gave a realistic estimate of this reduction. The $t$ scores (mean $=50$, standard deviation $=10)$ of pros and cons were calculated as described by Rakowski et $a .^{8}$ Bivariate analysis included cross tabulation, $\chi^{2}$ tests of independence, and 
Table 3 Characteristics associated with overestimation of mammography screening efficacy among 639 women of ages 40 to 80 years who stated that mammography screening prevents deaths attributable to breast cancer (Geneva, Switzerland) *

\begin{tabular}{|c|c|c|c|c|}
\hline \multirow[b]{3}{*}{ Characteristic } & \multicolumn{3}{|c|}{$\begin{array}{l}\text { Estimated proportion of death from breast } \\
\text { cancer prevented by mammography } \\
\text { screening }\end{array}$} & \multirow[b]{3}{*}{ p Value } \\
\hline & \multirow{2}{*}{$\begin{array}{l}\text { One quarter } \\
\text { or more } \\
\text { Number }\end{array}$} & \multicolumn{2}{|c|}{$\begin{array}{l}\text { One half or more } \\
\text { (overestimate) }\end{array}$} & \\
\hline & & Number & Raw \% & \\
\hline Overall & 639 & 466 & 72.9 & \\
\hline Pros (approximate tertiles) & & & & $<0.001 \neq$ \\
\hline Lowest & 213 & 140 & 65.7 & \\
\hline Middle & 186 & 136 & 73.1 & \\
\hline Highest & 234 & 188 & 80.3 & \\
\hline Cons (approximate tertiles) & & & & $<0.001 \ddagger$ \\
\hline Lowest & 262 & 215 & 82.1 & \\
\hline Middle & 215 & 149 & 69.3 & \\
\hline Highest & 157 & 99 & 63.1 & \\
\hline $\begin{array}{l}\text { Reluctant to pay Swiss Fr } 200 \text { for a } \\
\text { mammogram } \$\end{array}$ & & & & 0.03 \\
\hline Yes & 67 & 43 & 64.2 & \\
\hline No & 497 & 379 & 76.3 & \\
\hline $\begin{array}{l}\text { Perceived an organised programme of } \\
\text { mammography screening as useful for } \\
\text { themselves }\end{array}$ & & & & 0.18 \\
\hline Yes & 495 & 367 & 74.1 & \\
\hline No & 101 & 68 & 67.3 & \\
\hline $\begin{array}{l}\text { Intended to have a mammogram in the } \\
\text { future }\end{array}$ & & & & $<0.001$ \\
\hline Yes & 458 & 353 & 77.1 & \\
\hline No & 144 & 89 & 61.8 & \\
\hline First degree relative with breast cancer & & & & 0.40 \\
\hline Yes & 48 & 38 & 79.2 & \\
\hline No & 591 & 428 & 72.4 & \\
\hline $\begin{array}{l}\text { Subjective risk of breast cancer as compared } \\
\text { with other women }\end{array}$ & & & & 0.002 \\
\hline Lower & 96 & 68 & 70.8 & \\
\hline Similar & 330 & 241 & 73.0 & \\
\hline Higher & 47 & 44 & 93.6 & \\
\hline No opinion & 154 & 103 & 66.9 & \\
\hline $\begin{array}{l}\text { Have had a mammogram in the past two } \\
\text { years }\end{array}$ & & & & 0.29 \\
\hline Yes & 326 & 244 & 74.8 & \\
\hline No & 313 & 222 & 70.9 & \\
\hline Visit to a gynaecologist during the past year & & & & 0.35 \\
\hline Yes & 506 & 375 & 74.1 & \\
\hline No & 84 & 58 & 69.0 & \\
\hline $\begin{array}{l}\text { Mammography recommended by a } \\
\text { gynaecologist during the past two years }\end{array}$ & & & & 1.0 \\
\hline Yes & 339 & 253 & 74.6 & \\
\hline No & 258 & 193 & 74.8 & \\
\hline Age $(y)$ & & & & 0.15 \\
\hline $40-49$ & 204 & 150 & 73.5 & \\
\hline $50-69$ & 371 & 276 & 74.4 & \\
\hline $70-80$ & 64 & 40 & 62.5 & \\
\hline Married & & & & 0.93 \\
\hline Yes & 411 & 300 & 73.0 & \\
\hline No & 223 & 164 & 73.5 & \\
\hline Citizenship & & & & $<0.001$ \\
\hline Swiss & 487 & 373 & 76.6 & \\
\hline Other & 149 & 92 & 61.7 & \\
\hline Education level (y) & & & & 0.12 \\
\hline$\leqslant 10$ & 166 & 114 & 68.7 & \\
\hline$>10$ & 440 & 331 & 75.2 & \\
\hline Monthly net income per person (Swiss Fr) & & & & 0.39 \\
\hline$\leqslant 1500$ & 114 & 82 & 71.9 & \\
\hline$>1500$ & 415 & 316 & 76.1 & \\
\hline
\end{tabular}

*Analysis restricted to women who stated that mammography screening prevent about one quater (realistic estimators), or about one half or three fourths of deaths attributable to breast cancer in women over age 50 (overestimators). †As a result of missing data, numbers may sum to less than 639. $\ddagger \chi^{2}$ test of linear trend. \$Amount charged for a screening mammogram in Geneva. $\mathbb{\text { In }}$ December 2000, 1 Swiss Fr was equal to $£ 0.40$.

Mantel-Haenszel $\chi^{2}$ test for linear trend, when appropriate.

We used logistic regression to adjust comparisons. In these analyses, we included only possible causes of beliefs about screening efficacy, ${ }^{15}$ to avoid overadjustment. Hence, pros, cons, reluctance to pay, perceived usefulness of a screening programme, and intention to undergo mammography were omitted from regression analysis as these dimensions are more likely consequences than causes of perceived efficacy of screening. Remaining variables that predicted lack of opinion or overestimation of benefit at $\mathrm{p}<0.20$ in bivariate analysis were included into two logistic regression models, one for each aspect of perceived efficacy. A backward strategy was used to exclude variables that did not contribute to at least one model. All reported tests were two sided; a significance level of $p<0.05$ was used.

\section{Results}

Of 1334 eligible women (French speaking, alive, and Geneva residents), 958 responded $(71.8 \%)$. Data from the Population Bureau indicated that eligible participants were younger on average than non-participants (mean: 56.4 years versus 58.3 years, $p=.005$ ), and more likely to be married $(62.1 \%$ versus $55.6 \%, \mathrm{p}=0.03)$ and Swiss $(76.8 \%$ versus $62.1 \%, \mathrm{p}<0.0001)$. After exclusion of 49 women who had a past history of breast cancer, 909 observations remained for analysis. In this group, 895 (98.5\%) women answered the item on mortality reduction. Only $19.3 \%$ stated correctly that regular screening prevents "about one fourth" of deaths from breast cancer; $29.7 \%$ thought that screening prevents "about one half" of deaths, 22.3 "about three fourths", $26.0 \%$ "didn't know", and $2.6 \%$ thought that screening prevents no death (table $1)$.

The characteristics of the study sample are presented in table 2 , column 1 .

LACK OF OPINION ABOUT EFFICACY

In bivariate analysis, women who gave an opinion about screening efficacy and those who "did not know" differed significantly across all characteristics examined, except family history of breast cancer, citizenship, and income (table 2). Globally, women in the no opinion group were older and less educated, tended to have less favourable attitudes toward mammography screening, declined to assess their risk of developing breast cancer relative to other women, and had had fewer contacts with gynecologists.

\section{OVERESTIMATION OF EFFICACY}

Among the 639 women who believed that mammography screening reduces breast cancer mortality, six characteristics were significantly associated with overestimation of screening efficacy (table 3): a higher score of pros and a lower score of cons, willingness to pay for a mammogram, intent to undergo a mammogram in the future, a higher subjective risk of breast cancer, and Swiss nationality.

\section{MULTIVARIATE ANALYSIS}

In multivariate analysis, not having had a mammogram in the past two years nor a recent visit to a gynaecologist, having no opinion about one's risk of breast cancer, and being of ages 70 to 80 were independently associated with lack of opinion about reduction in breast cancer mortality (table 4). Only estimating one's own risk of breast cancer as above average and being Swiss independently predicted overestimation of mammography benefit. 
Table 4 Results of logistic regression analysis of characteristics associated with perceived efficacy of mammography screening in a random sample of women of ages 40-80 years residing in Geneva, Switzerland

\begin{tabular}{|c|c|c|c|c|}
\hline \multirow[b]{2}{*}{$\begin{array}{l}\text { Have had a mammogram in the past two } \\
\text { years }\end{array}$} & \multicolumn{2}{|c|}{$\begin{array}{l}\text { Had no opinion about } \\
\text { mammography efficacy } \\
\text { versus Had an opinion } \\
\text { aOR }(95 \% \text { CI) }\end{array}$} & \multicolumn{2}{|c|}{$\begin{array}{l}\text { Overestimate versus } \\
\text { Realistic estimate aOR } \\
(95 \% \text { CI) }\end{array}$} \\
\hline & & $\mathrm{p}=0.009$ & & $\mathrm{p}=61$ \\
\hline No & 1.0 & & 1.0 & \\
\hline Yes & $\begin{array}{l}0.57 \\
(0.39,0.87)\end{array}$ & & $\begin{array}{l}1.1 \\
(0.73,1.7)\end{array}$ & \\
\hline Visit to a gynaecologist during the past year & & $\mathrm{p}=0.02$ & & $\mathrm{p}=0.76$ \\
\hline No & 1.0 & & 1.0 & \\
\hline Yes & $\begin{array}{l}0.60 \\
(0.39,0.91)\end{array}$ & & $\begin{array}{l}1.1 \\
(0.63,1.9)\end{array}$ & \\
\hline $\begin{array}{l}\text { Subjective risk of breast cancer as compared } \\
\text { with other women }\end{array}$ & & $\mathrm{p}<0.001$ & & $\mathrm{p}=0.04$ \\
\hline Lower & 1.0 & & 1.0 & \\
\hline Similar & $\begin{array}{l}0.98 \\
(0.57,1.7)\end{array}$ & & $\begin{array}{l}1.1 \\
(0.64,1.9)\end{array}$ & \\
\hline Higher & $\begin{array}{l}0.47 \\
(0.15,1.5)\end{array}$ & & $\begin{array}{l}6.1 \\
(1.7,21.6)\end{array}$ & \\
\hline No opinion & $2.6(1.5,4.5)$ & & $\begin{array}{l}1.1 \\
(0.60,2.0)\end{array}$ & \\
\hline Age (y) & & $\mathrm{p}=0.04$ & & $\mathrm{p}=0.36$ \\
\hline $40-49$ & 1.0 & & 1.0 & \\
\hline $50-69$ & $\begin{array}{l}0.80 \\
(0.54,1.2)\end{array}$ & & $\begin{array}{l}1.1 \\
(0.71,1.7)\end{array}$ & \\
\hline $70-80$ & $\begin{array}{l}1.5 \\
(0.89,2.6)\end{array}$ & & $\begin{array}{l}0.69 \\
(0.35,1.4)\end{array}$ & \\
\hline Citizenship & & $\mathrm{p}=0.52$ & & $\mathrm{p}=0.001$ \\
\hline Swiss & 1.0 & & 1.0 & \\
\hline Other & $\begin{array}{l}1.1 \\
(0.77,1.7)\end{array}$ & & $\begin{array}{l}0.50 \\
(0.33,0.77)\end{array}$ & \\
\hline
\end{tabular}

$\mathrm{aOR}=$ adjusted odds ratio $\mathrm{CI}=$ confidence intervals.

\section{Discussion}

Despite recent controversy, ${ }^{16}$ meta-analyses summarising the best available evidence have concluded that breast cancer mortality for women aged 50 to 74 years is about $25 \%$ to $30 \%$ lower in women who undergo regular mammography screening. ${ }^{7} 17$ In our study, only one of five women provided an estimate of benefit in this range, while one of four was uninformed about mammography screening efficacy and one of two estimated that mammography screening reduces breast cancer mortality by $50 \%$ to $75 \%$. This finding quantifies and extends to a general population a previous observation of overestimation of mortality reduction reported in a clinic-based sample of younger American women. ${ }^{19}$ Our results are also in line with a recent report that $55 \%$ of women representative of the US general population expected mammography screening to cut risk of death attributable to breast cancer by one half. ${ }^{20}$

Furthermore, our study showed that misconceptions about the percentage of breast cancer deaths prevented by mammography screening were consistently associated with attitudes toward mammography screening and with the intention to get a mammogram in the future. Hence inaccurate estimation of screening efficacy may affect women's overall perception of the balance between positive and negative consequences of mammography screening. Together with the finding that few women assess realistically the efficacy of mammography screening, this result indicates that most women in the general population are not in a position to provide truly informed consent before undergoing breast cancer screening, unless a more balanced information is provided to them in due course.
KEY POINTS

- Whether women in the general population are correctly informed about the benefits of mammography screening is unclear.

- In this study, we show that most women are either uninformed or overestimate the impact of mammography screening on breast cancer mortality.

- Unwarranted optimism about the efficacy of mammography screening was associated with a propensity to undergo mammography screening.

- Therefore, there is a conflict between the objective of achieving high participation rates in mammography screening programmes and providing women with accurate information about reduction in mortality from breast cancer attributable to mammography screening.

Multivariate analysis of risk factors for unrealistic estimates of screening efficacy supports the hypothesis that women receive inadequate information about mammography screening. Women who had had closer contacts with the preventive health care system were more likely to have an opinion about the efficacy of mammography screening, but did not provide more realistic estimates of mammography efficacy. Few socioeconomic variables were associated with inaccurate estimation of effectiveness. After adjustment, the oldest women (70 to 80 years old) were less likely to have an opinion about mortality reduction attributable to screening and Swiss citizens more likely to overestimate this reduction. However, multivariate models tend to favour proximate causes (in this case, contacts with providers of preventive care services and subjective risk of breast cancer) and disregard more distal causes, such as sociodemographic characteristics. ${ }^{21}$ Therefore, results of bivariate analysis should not be overlooked as they suggest that knowledge of the impact of screening on breast cancer mortality was deficient among the less educated and unmarried women.

Some limitations to this study should be considered. Our questionnaire assessed only the relative reduction of breast cancer mortality achievable through mammography screening; some women may have preferred mortality reduction on an absolute scale. Our response choices did not consider the possibilities that mammography screening may increase breast cancer mortality or prevent all deaths from breast cancer; the inclusion of these options may have changed the distribution of respondents among the other opinions. On average, non-respondents were older than respondents, and more likely to be unmarried and foreigners. These characteristics are often associated with a lower level of knowledge about health related issues. Furthermore, there was no organised programme of breast cancer screening in Geneva at the time of the survey. But previous research has shown that women from areas where such programmes have been in 
effect for several years are not necessarily better informed about the benefit of mammography screening. ${ }^{19} 20$ Finally, causality cannot be inferred from a cross sectional study.

Our results and those of previous research suggest that the widespread use of a marketing approach to information about mammography screening has been effective in imparting unwarranted optimism among women in the general population. ${ }^{5} 1920$ 22-24 Programme managers should take the current level of misinformation into account when designing information intended for screening participants. ${ }^{25-29}$ But our data also suggest that fully informed consent may reduce participation and hence the public health effectiveness of the programme. Therefore, we defend the opinion that evaluation criteria for screening programmes should be revised. ${ }^{30}$ Screening programmes should be judged not only by the level of participation achieved, but also by the proportion of women who were able to reach a truly informed decision about mammography screening, based on a balanced account of risks and benefits.

Contributors

EC was involved in all aspects of the research (guarantor). TP helped to secure the funding, contributed to the planning of the study, the development of the survey instrument, the interpretation of the data, and the writing of the paper.

Funding: Geneva Cancer League, Geneva, Switzerland. Conflicts of interest: none.

1 Coulter A. Evidence-based patient information. $B M \mathcal{F}$ 1998;317:225-6.

2 Tornberg SA. Screening for early detection of cancerethical aspects. Acta Oncol 1999;38:77-81.

3 Slaytor EK, Ward JE. How risks of breast cancer and benefits of screening are communicated to women: analysi of 58 pamphlets. BMF 1998;317:263-4.

4 Wright CJ, Mueller CB. Screening mammography and public health: the need for a perspective. Lancet 1995;346:2932.

5 Baines C. Women and breast cancer: is it really possible for the public to be well informed? Can Med Assoc f 1992;146 2147-8.

6 Kuppermann M, Nease RF. What is a good decision? Effective Clinical Practice 1999;2:187-8.

7 Kerlikowske K, Grady D, Rubin SM, et al. Efficacy of screening mammography: a meta-analysis. $\mathfrak{f} A M A$ 1995; 273:149-54.

8 Rakowski W, Fulton JP, Feldman JP. Women's decision making about mammography: a replication of the relationship between stages of adoption and decisional balance. Health Psychol 1993;12:209-14.
9 Prochaska JO, Velicer WF, Rossi JS, et al. Stages of change and decisional balance for 12 problem behaviors. Health Psychol 1994;13:39-46.

10 Rakowski W, Dube CA, Goldstein MG. Considerations for extending the trantheoretical model of behavior change to screening mammography. Health Educ Res 1996;11:77-96.

11 Rakowski W, Andersen MR, Stoddard AM, et al. Confirmatory analysis of opinions regarding the pros and cons of mammography. Health Psychol 1997;16:433-41.

12 Pearlman DN, Rakowski W, Clark MA, et al. Why do women's attitudes toward mammography change over time? Implications for physician-patient communication. Cancer Epidemiol Biomarkers Prev 1997;6:451-7.

13 Stoddard AM, Rimer BK, Lane D, et al. Underusers of mammogram screening: stage of adoption in five U.S. populations. Prev Med 1998;27:478-87.

14 Lipkus IM, Rimer BK, Strigo TS, Relationships among objective and subjective risk for breast cancer and objective and subjective risk for breast cancer and
mammography stages of change. Cancer Epidemiol Biomarmammography stages of chan

15 Ajzen I, Fishbein M. Understanding attitudes and predicting behavior. Englewood Cliffs, NJ: Prentice-Hall, 1980.

16 Gotzsche PC, Olsen O. Is screening for breast cancer with mammography justifiable? Lancet 2000;355:129-34.

17 Nystrom L, Rutqvist L, Wall S, et al. Breast cancer screening with mammography: overview of Swedish randomized trials. Lancet 1993;341:973-8.

18 Wald NJ, Chamberlain J, Hackshaw A, on behalf of the Evaluation Committee Consensus Committee. Consensus statement: report of the European Society for Mastology Breast Cancer Screening Evaluation Committee (1993). Breast 1993;2:209-16.

19 Black WC, Nease RF, Tosteson A. Perceptions of breast cancer risk and screening effectiveness in women younger cancer risk and screening effectiveness in women younge

than 50 years of age. F Natl Cancer Inst 1995;87:720-31.
Schwartz LM, Woloshin S, Sox HC, et al. US women's attitudes to false positive mammography results and detection of ductal carcinoma in situ: cross sectional survey. $B M F$ 2000;320:1635-40.

21 Leon DA. Failed or misleading adjustment for confounding. Lancet 1993;342:479-81.

22 Woloshin S, Schwartz LM, Byram SJ, et al. Women's understanding of the mammography screening debate. Arch Intern Med 2000;160:1434-40.

23 Barratt A, Cockburn J, Furnival C, et al. Perceived sensitivity of mammography screening: women's views on test accuracy and financial compensation for missed cancers. $\mathcal{f}$ Epidemiol Community Health 1999;53:716-20.

24 Yanovitzky I, Blitz CL. Effect of media coverage and physician advice on utilisation of breast cancer screening by 34.

25 Wolf AMD, Becker DM. Cancer screening and informed patient discussions: truth and consequences. Arch Intern Med 1996;156:1069-72

26 Pellissier JM, Venta ER. Introducing patient values into the decision making process for breast cancer screening. Women Health 1996;24:47-67.

27 Malm HM. Medical screening and the value of early detection: when unwarranted faith leads to unethical recommendations. Hastings Cent Rep 1999;29:26-37.

28 Ward J. Population-based mammographic screening: does 'informed choice' require any less than full disclosure to individuals of benefits, harms, limitations and consequences? Aust N Z F Public Health 1999;23:301-4.

29 Kerlikowske K. Women should be fully informed of the potential benefits and harms before screening mammograpotential benefits and harms before

30 Foster P, Anderson CM. Reaching targets in national cervical screening programme: are current practices unethical? $\mathcal{f}$ Med Ethics 1998;24:151-7. 